\title{
Antimicrobial textile: recent developments and functional perspective
}

\author{
Rehan Gulati $^{1}$ - Saurav Sharma ${ }^{2} \cdot$ Rakesh Kumar Sharma $^{1}$ (D)
}

Received: 10 April 2021 / Revised: 5 July 2021 / Accepted: 7 July 2021 /

Published online: 13 July 2021

(c) The Author(s), under exclusive licence to Springer-Verlag GmbH Germany, part of Springer Nature 2021

\begin{abstract}
Antimicrobial textiles are functionally active textiles, which may kill the microorganisms or inhibit their growth. The present article explores the applications of different synthetic and natural antimicrobial compounds used to prepare antimicrobial textiles. Different types of antimicrobial textiles including: antibacterial, antifungal and antiviral have also been discussed. Different strategies and methods used for the detection of a textile's antimicrobial properties against bacterial and fungal pathogens as well as viral particles have also been highlighted. These antimicrobial textiles are used in a variety of applications ranging from households to commercial including air filters, food packaging, health care, hygiene, medical, sportswear, storage, ventilation and water purification systems. Public awareness on antimicrobial textiles and growth in commercial opportunities has been observed during past few years. Not only antimicrobial properties, but its durability along with the color, prints and designing are also important for fashionable clothing; thus, many commercial brands are now focusing on such type of materials. Overall, this article summarizes the scientific aspect dealing with different fabrics including natural or synthetic antimicrobial agents along with their current functional perspective and future opportunities.
\end{abstract}

Rakesh Kumar Sharma

rakeshkumar.sharma@jaipur.manipal.edu; r.18sharma@gmail.com

1 Department of Biosciences, Manipal University Jaipur, Jaipur-303007, Rajasthan, India

2 Department of Fashion Design, Manipal University Jaipur, Jaipur-303007, Rajasthan, India 


\section{Graphic abstract}

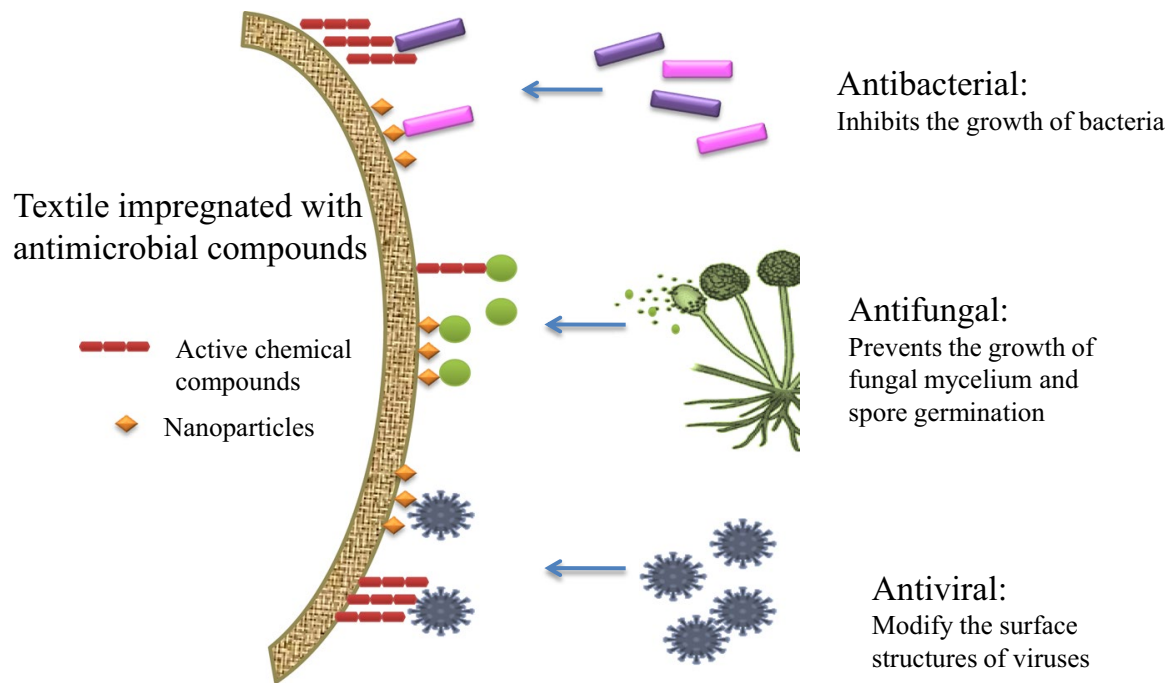

Keywords Antimicrobial $\cdot$ Fabric $\cdot$ Textile $\cdot$ Antibacterial $\cdot$ Clothing

\section{Introduction}

Textiles are omnipresent and play an essential part in human society. Cloths may contain certain types of microbes, which has been recently discussed as clothing microbiology and the effect and interaction of cloths with human skin microflora [1]. Coatings of natural antimicrobial agents on the textiles or fabrics date back to ancient times, when the Egyptians used spices and herbal coatings on cloths to prepare the mummy wrap. Traditionally, the Chinese used bamboo fibers, which contained an antimicrobial compound called 'Bamboo-kun' for housing structure. Bamboo fibers have also been explored for their natural antibacterial and antifungal properties, which are mediated by 2-6-dimethoxy-p-benzoquinone and dendrocin [2]. Application of antibiotics developed during the Second World War; at the same time, the use of antimicrobials to prevent textiles from rotting was also in demand. Tents, tarpaulins and truck covers were required to be protected from microbial attack during heavy rain and snow that would destroy fibers and also increase the chances of infection. To protect the fabric from microbial colonization and increase their durability, several military fabrics were treated with antimony salts, copper and a mixture of chlorinated waxes, which not only stiffened the fabrics but also gave them a distinct odor [3]. During initial times, the side effects of these antimicrobials were not considered, however, more attention was paid toward the adverse effects of these chemicals on the environment and health. The concept of safer antimicrobial compounds and textiles came into existence 
following the publication of Rachel Carson's book Silent Spring in 1962. Different sectors including ecologists, scientists, industrialists and chemists worked collectively to produce eco-friendly antibiotics [4].

In the present era, antimicrobial textiles are very helpful in hospitals, environment and places that are prone to microbes, which are baleful. The clothes are worn by the patients, healthcare workers and doctors may have a lot of microbes present on them, which can be transmitted easily from one person to another. Commercial opportunities abound for antimicrobial fabrics whenever it is about controlling the spread of infectious microorganisms [5]. Antimicrobial textiles can be termed based on their specificity against microbes, i.e., antibacterial, antifungal, or/and antiviral. Several antimicrobial textiles may also act against bacteria, fungi and viruses simultaneously. Some chemicals may be used to target a broad range of microbes and are generally termed as antimicrobial [6]. In common public area including hotels, restaurants, or trains such type of fabric is highly demanded, e.g., the towel which is used to mop up fluids, curtain and carpet could be a source of infection. There are also noticeable unfulfilled requirements for odor control, which is another expanding research area in this field. The textile may contain several microorganisms that are anathema and may transfer from an infected person to others. The only possible and effective way for reducing the microbial load from textile is by continuous laundering of clothes but this case is not possible in hospitals where there are continuous shifts. On the other hand, another way to reduce the chances of microbial infection from one person to others through the textile is by developing antimicrobial textiles. These antimicrobial textiles may also be useful for the people involved in sanitary-related work and those who are working in sewage treatment, where there is a high risk of getting infected. Surface modification of the textile including electrospinning, nanotechnologies, plasma treatment, polymerization, microencapsulation and sol-gel techniques has been done to impart some novel functional properties to textile, e.g., water-repellent, flame-retardant and antibacterial activity [7].

Antimicrobial winter wear is gaining importance as these clothes are not washed frequently and rarely exposed to sunlight. These clothes are generally stored for a longer time, which may enable the growth of microbes and thus antimicrobial type fabric may be an appropriate option. Similarly, the antimicrobial textiles may also be useful in those places where non-plastic bags are used. Food packaging which generally involves degradable material is safer for the environment as well as does not affect the food properties, however, the concept of antimicrobial coating in such wrappers is important to reduce the growth of pathogenic and food spoilage microbes. Primarily, the antimicrobial textile is required by the following sectors along with the appealing combination of color, print and design:

- Apparel: caps, jackets, sanitary pads, sportswear, undergarment, winter wear

- Commercial: carpets, covering for seats, window, vehicle, etc.; dusting cloths, military fabric, tent, uniform

- Health care: bandage, earbuds, scrub, mask, lab coats, protective kits

- Households: bedding, carpet, cover, curtains, mop, pillows, towel 
The present work deals with the recent update in the development and applications of antimicrobial textile. A word cloud has been prepared using this article to portray the essence of the whole article (Fig. 1).

\section{Active antimicrobial agents}

\section{Nanoparticles}

Among different compounds, nanoparticle-based coatings are quite common in both natural as well as synthetic textiles. Silver nanoparticles (AgNPs) possess strong toxicity toward a broad range of microbes with lower toxicity toward human cells along with long-term durability and increased dyeability. Silver (Ag) nanomaterials are well recognized for their self-cleaning and antimicrobial activity [8]. AgNPs $(\sim 10 \mathrm{~nm}$ in size) have also demonstrated antiviral activity against SARS-CoV-2 (the causative virus of COVID-19) [9]. Besides silver, other metals and metal oxide nanoparticles including titanium, tin, zinc, gold and copper have also been applied on different natural as well as synthetic textiles. As suggested the antimicrobial activity of functionalized CuONPs coated textile materials against Gram-positive and Gramnegative bacteria can be attributed to three main mechanisms, i.e., the release of copper ions, the direct contact of $\mathrm{CuO}$ NPs with bacteria and the production of reactive oxygen species [10].

Biosynthesis and applications of nanostructured inorganic materials have got its importance in the development of antimicrobial textile. Selenium brooms were synthesized using almond skin extract showed time-dependent changes in the

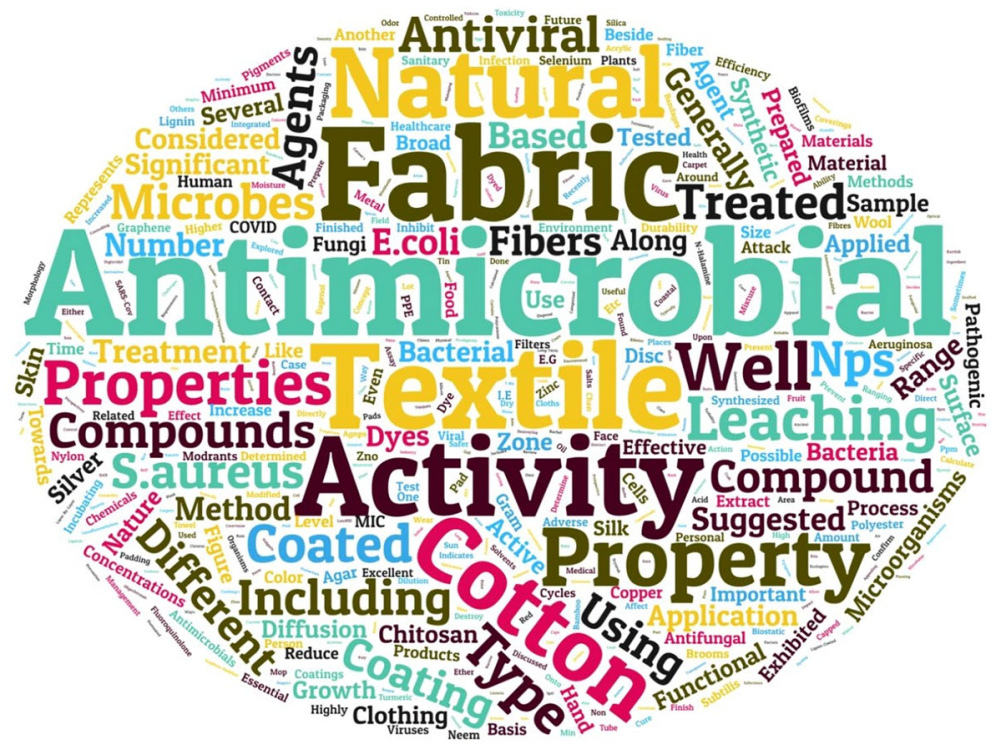

Fig. 1 A word cloud based on the present article. Larger size of the word represents higher frequency 
morphology from NPs in $15 \mathrm{~s}$ to selenium brooms in 45 min. Cotton-coated fabric with these structures exhibited activity against Bacillus subtilis [11]. Functional ecofriendly nanohybrid material synthesized using oligochitosan (obtained from crab shells) and nano-silica (obtained from rice husk) was resistant against Phytophthora infestans fungal attack, which points toward advanced research in the green agricultural application [12].

Agglomeration prevention, desired morphology and uniform size of nanoparticles have always been challenging in the NPs-related studies. Capping with ligands is generally used to overcome such challenges. Several natural capping agents have been used and are also well coated on the fabric. Seaweed capped zinc oxide nanoparticles (SW-ZnO NPs) were coated on cotton fabric using pad-dry-cure technique, which demonstrated its antibacterial against both Gram-positive (Staphylococcus aureus and Streptococcus pyogenes) and Gram-negative (Escherichia coli and Klebsiella aerogenes) bacteria [13]. Similarly, another natural capping agent, date seed extract was used to prepare capped $\mathrm{ZnO}$ NPs, which also demonstrated the antimicrobial activity and UV protectant property in cotton fabric [14]. Amino-capped $\mathrm{TiO} 2$ NPs coated functional cotton fabric was fabricated using two-step sol-gel and hydrothermal method demonstrated an effective antibacterial activity against $S$. aureus and E. coli [15].

Cellulose-based fabric requires pre-activation or pre-treatment to attain efficient stability of the NPs on the surface. Some human skin friendly bio-adhesive chemicals or methods need to be explored to develop a durable functional textile. Simultaneous sonochemical deposition of ZnO NPs using an enzymatic cross-linked phenolic network of gallic acid demonstrated high antibacterial efficiency even after several washing cycles in hot water [16].

\section{Natural compounds}

In addition to curcumin, there are many natural active agents have been extracted and used to develop antimicrobial fabric. Application of plant extract, essential oils as well as animal products, e.g., honey, have also been used in fabrics for managing wound infections. Several natural dyes, pigments and mordants have also been explored for their antimicrobial activity.

Sustainable antimicrobial textile finishing may be developed by using some natural compounds like cyclodextrins. These cyclic oligosaccharides have a hydrophilic outer surface and a lipophilic central cavity. Application of cyclodextrin and its derivatives ( $\alpha$-cyclodextrin, $\beta$-cyclodextrin and $\gamma$-cyclodextrin) are increasing in the textile industry [17]. Lignin provides resistance against microbial attack in plants. This dark-colored phenolic compound is generally removed during the processing to get cellulose fibers. A lignin-coated fabric made from sugarcane bagasse exhibited antibacterial activity against Staphylococcus epidermidis. The lignin coating concentration was based on its MIC, which suggested that the bacterial growth could be inhibited to prevent further propagation within $6 \mathrm{~h}$ of contact [18]. Chitosan is often used in antimicrobial textile preparation and processing because of its antimicrobial and anti-odor property. Chitosan is a cationic polysaccharide, which is obtained by 
alkaline deacetylation of chitin. Application of chitosan hydrogel on cellulosic fabric imparted antibacterial activity against $S$. aureus, E. coli and Listeria monocytogenes [19]. Contrarily, a report suggested that the antimicrobial properties were not significantly affected by chitosan when the cotton and polyester fabrics were coated in a combination of silica sols and chitosan [20]. However, edible chitosan/pectin-based silver nanoparticle films from natural biodegradable polymers demonstrated effective antibacterial activity against $E$. coli. These antimicrobial films may increase the shelf life of the products and may be used for food packaging purpose [21].

\section{Other chemicals and treatments}

Halogens have been used in the treatment of fabric to impart antimicrobial property. Functional fibers having highly effective antibacterial property was fabricated by the introduction of an $\mathrm{N}$-halamine structure on a polydopamine-based coating. $\mathrm{N}$-halamine functionalized polydopamine-based coatings exhibited antibacterial activity against $S$. aureus and E. coli [22]. Halogenated phenols, e.g., chlorophenols have also been used in antimicrobial textile finishes. Active polymers based on biguanides (polycationic amines) may destroy the bacterial cell by electrostatic attractions [23]. Cotton fabrics were coated with silicon and nitrogen-containing compound, poly [3-(5,5-cyanuricacidpropyl)-siloxane-co-trimethyl ammoniumpropyl siloxane chloride] with phytic acid by layer-by-layer assembly (Cotton-PEI/ (PCQS/PA)30-Cl). The treated cotton fabrics reduced $100 \%$ E. coli and S. aureus within 1 min of contact time [24].

Plasma treatment has been proposed as a low-cost and chemical-free method to modify the surface properties of different fabrics for incorporating eco-friendly rechargeable antimicrobial finishing. Cotton fabric treated with nitrogen plasma after padding with 5,5-dimethylhydantoin (pad-plasma-dry-cure) and chlorinated with sodium hypochlorite improved its antibacterial property against $S$. aureus [25]. Deposition of silver nanoparticles on plasma-activated surface exhibited antimicrobial property [26]. Similarly, dielectric barrier discharge plasma-treated polyamide 6,6 fabric showed higher Ag NPs deposition [27].

\section{Types of antimicrobial textiles}

Depending upon the treatment and antimicrobial compound used, the antimicrobial fabric may be leaching type or non-leaching type, while based on its mechanism it can be biocide or biostatic. The biocides kill the microorganisms, whereas the biostatics inhibits their growth. These biocides and biostatics may be further categorized on the basis of targeting microorganisms, i.e., bacteria, fungi, or viruses (Table 1). For clothing's biostatic fabric is preferred as they preserve the natural bacterial flora of the skin and have no adverse effect on human skin, while on the other hand, a biocidal fabric is preferred for medical and environmental applications.

There are a number of fabrics that may possess an intrinsic antimicrobial property, which may not be active against specific pathogenic microbes, thus having a 


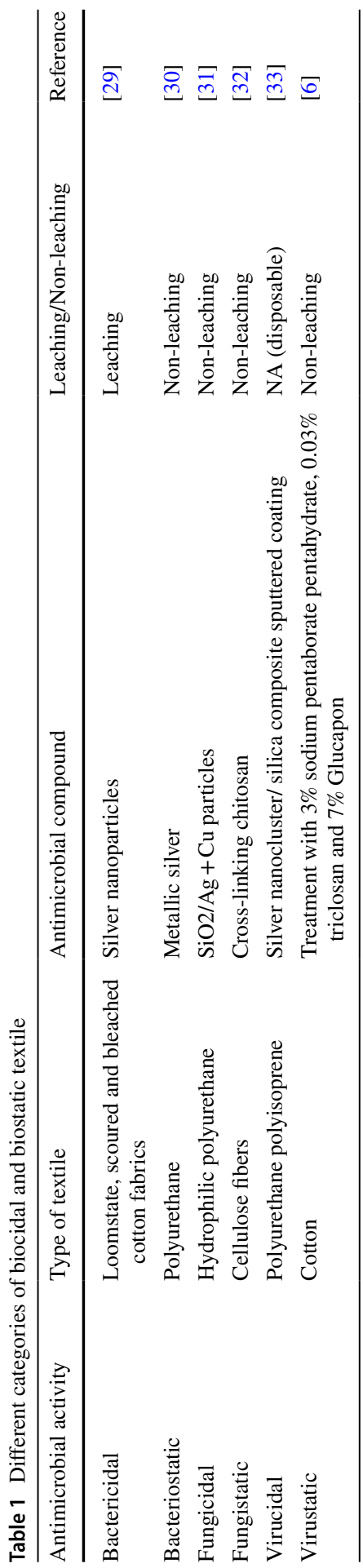


narrow antimicrobial spectrum. Incorporation of antimicrobial agents is preferred into the fabric, which allows a broad range of antimicrobial attributes and may be applied to different fabrics of choice. Most of the antimicrobial agents used in the textile industry utilize a controlled release or leaching mechanism in the presence of moisture. The leaching action leads to the gradual decrease in the active substance. Additives can be introduced inside the fiber matrix during spinning extrusion or they can be applied by conventional coating or impregnation process such as padding or exhaustion to textile surfaces [28].

\section{Antibacterial textile}

There are a number of methods used for determination of the antimicrobial properties of the textile samples. In some cases, the active agent (or chemical composition) can be tested alone. Antibacterial activity of the active agent may be tested by using different methods as suggested by Clinical and Laboratory Standards Institute (CLSI) [34]. The most conventional, efficient and reliable broth microdilution methods based on the visual determination (optical density measurement) are illustrated in Fig. 2. The minimum inhibitory concentration (MIC) value is defined as the lowest concentration able to inhibit the growth of the tested bacterial strains. The minimum bactericidal concentration (MBC) is determined by sub-culturing the cells exposed to different concentrations of the antimicrobial compound, used to evaluate MIC, in fresh growth medium and defined when no growth is observed [35].

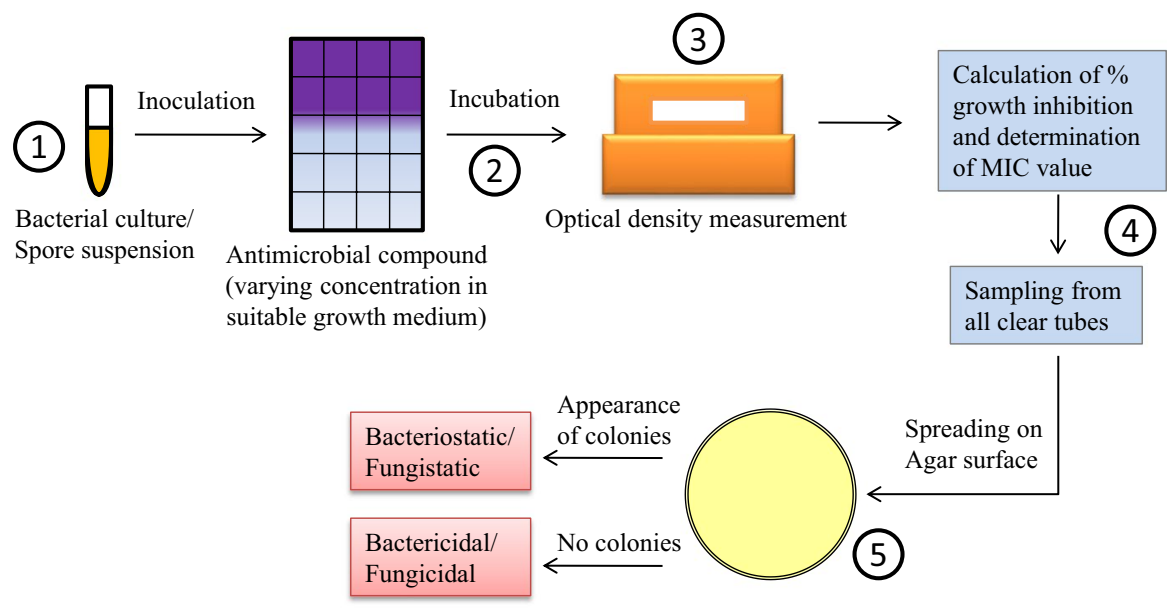

Fig. 2 Microtube dilution method for the evaluation of antimicrobial potential of active agent: (1) bacterial culture or spore suspension of test organisms with known cell/spore concentration, (2) series of varying concentration of antimicrobial compound in sterilized growth medium along with appropriate positive and negative controls, (3) visual growth or optical density (OD) measurements after incubation, (4) calculation of $\mathrm{IC}_{50}$, no visual growth represents MIC values and (5) confirmation of bactericidal/fungicidal or bacteriostatic/fungistatic nature of antimicrobial compound by spreading the sample from MIC wells 
The tube dilution method may also be used for the calculation of Inhibitory concentrations $\left(\mathrm{IC}_{50}\right)$ against microorganisms, which is an important factor to assess the efficiency of antimicrobial compounds. Most of the experiments were based on the direct coating of these compounds with maximum possible adherence as leaching type fabric was generally prepared. However, some studies used MIC value for the impregnation of NPs as demonstrated during the preparation of antibacterial bandages, which were impregnated with different NPs including Ag NPs, ZnO NPs and mixed Ag/ZnO NPs. Among these nanoparticles Ag NPs were the most effective against Acinetobacter baumannii and Pseudomonas aeruginosa [36]. MIC determination of the antimicrobial compound is required to inhibit the growth bacteria, which ultimately decides the material price. This price-performance index when calculated for commercial silver nanoparticles and lignin extracts from sugarcane bagasse as antimicrobial agents to develop antimicrobial textile, suggested that the utilization of bio-based agents may be economic [18].

Confirmation of the bactericidal and bacteriostatic nature of the compounds can be done through the re-inoculating the clear broth used for MIC determination of the antimicrobial compound (Fig. 2). The antimicrobial property of the textile can be determined by 'Fabric Disc Diffusion Assay'. A circular disk of sample fiber is placed on the inoculated agar surface. A zone of inhibition appeared after incubation confirms the antimicrobial property of the sample (Fig. 3).

Disk diffusion method was applied to find out the antibacterial activity of Helichrysum arenarium methanolic extract against $S$. aureus and $E$. coli. Dyed wool fabrics with these natural dyestuffs also demonstrated significant antimicrobial activity [37]. Some antimicrobial may be selective and may be used against specific bacteria as in the case of nano selenium brooms when tested against $S$. aureus, B. subtilis, $P$. aeruginosa, E. coli and Proteus vulgaris, minimum inhibitory concentrations and minimum bactericidal concentrations indicated its activity against only B. subtilis, thus suggested to be specifically used in operation theaters to decrease the incident of Bacillus-related Bacteraemia [11].

\section{Antifungal textile}

Disk diffusion and tube dilution, both methods can be used for the determination of the fungicidal and fungistatic nature of the textile (Figs. 2, 3). Filamentous fungi are

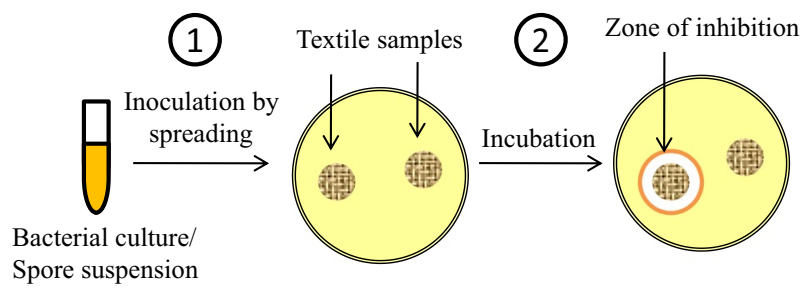

Fig. 3 Fabric disk diffusion assay: (1) spreading of test bacterial culture or spore suspension on agar plates and placing of circular disk of sample fabrics and (2) measurement of zone of inhibition after incubation 
considered the most fabric damaging organisms because of their ability to grow on a number of natural substrates. Cladosporium, Alternaria and Aspergillus are commonly encountered fungi among others. Antimicrobial fabrics prepared by synthesizing using modified silica by including $\mathrm{Ag}$ and $\mathrm{C}$, demonstrated a significant reduction in the growth of these fungi on it [38]. Cotton fabric coated with guanazole complexes with silver and zinc ions exhibited a broad range of antimicrobial property against bacterial as well as fungal pathogens, i.e., A. niger, Fusarium chlamydosporum and Penicillium sp. Besides antimicrobial property, these cotton fabrics coated with guanazole-metal complexes also demonstrated flame-retardant property [39]. Cellulose fibers containing fungal synthesized $\mathrm{ZnO}$ NPs using Phanerochaete chrysosporium demonstrated antimicrobial activity. These fibers showed antifungal activity against opportunistic pathogenic fungus A. niger, yeast Geotrichum candidum and also a wood degrading (cellulolytic) fungus $P$. chrysosporium [40].

\section{Anti-biofilm textile}

Most of the infectious diseases are directly linked to bacterial or fungal biofilms. Antimicrobial property of the textile may prevent the biofilm formation and may also reduce infections. Incorporation of antibacterial, anti-biofilm or anti-adhesive biocompatible NPs including inorganic $(\mathrm{Cu}, \mathrm{Zn}, \mathrm{Ga}, \mathrm{Si}$ or Ti based) different polymers and some biological components, e.g., antibacterial enzymes or functionalized lipids on textile is being developed through an industrial leadership program funded by European Commission, HORIZON 2020 [41].

To assess the anti-biofilm activity fabric sample is incubated overnight in broth medium inoculated with test bacterial strain. After rinsing with sterilized water after incubation, the visual biofilm can be observed using a high-power microscope, confocal laser scanning microscopy, or scanning electron microscopy. However, static biofilm assay using violet crystal staining is the most conventional method for the determination of anti-biofilm activity of nanoparticles and can be measured by spectrophotometrically [34]. Beside these methods, there are other methods have been discussed for the eradication or biofilms [42]. Cotton fabric modified with propylene imine dendrimers and their $\mathrm{Cu}(\mathrm{II})$ complexes exhibited good anti-biofilm activity against $P$. aeruginosa. The adhesion and biofilm formation on cotton fabrics was assessed using scanning electron microscopy and comparing with untreated and treated cotton fabrics [43]. Similarly, the gold nanoparticles containing fabrics negatively influenced the viability of developed biofilms of E. coli and S. aureus [44]. Cotton fabric treated with P1000Acrid dendrimer also hindered the development of $P$. aeruginosa -biofilm [45]. These anti-biofilm fabrics do not allow the adhesion of bacterial cells to the fibers or kill the cells, which comes in closer contact via different mechanisms, thus do not allow the microbes to grow and develop a biofilm.

\section{Antiviral textile}

Antiviral properties of the textile can be determined by following the standard protocol (ISO 18,184:2019 Textiles-Determination of antiviral activity of 
textile). The basic process for determination of an antiviral compound involves treating the virus with test compounds and then incubating with viral susceptible cells for plaque assay. For textile samples, some studies demonstrated that passing or filtering the viral suspension through the prepared textile and then incubating the filtrate with viral susceptible cells to determine the antiviral property. Cotton fabrics coated with $3 \%$ sodium pentaborate pentahydrate, $0.03 \%$ triclosan and 7\% Glucapon demonstrated a broad range antimicrobial activity bacteria, yeast and fungi. The treated cotton fabrics showed excellent antiviral activity against two tested viruses, adenovirus type 5 and poliovirus type 1 [6]. The sandwich test method was used to determine the antiviral activity of 1-chloro-2,2,5,5-tetramethyl-4-imidazolidinone coated nonwoven filters and the determination of the amount of surviving avian influenza viruses into embryonated chicken eggs confirmed the antiviral property of the filters [46]. Nanoparticles coated fabrics have also been developed as antiviral textile. AgNPs synthesized by radiochemical process were firmly immobilized on the surface of textile fabrics of cotton. The surface-modified fabric showed antiviral activity against Influenza A and Feline Calicivirus [47]. There are some potential antiviral polysaccharides, which may be used to combat the pathogen via pharmacotherapeutic applications. It was suggested that by coating masks, clothing and work surfaces, these antiviral polysaccharides may prevent spreading the viruses. These biocompatible and biodegradable polysaccharides are capable to bind to the spike proteins of the coronavirus. Layer-by-layer nanocoated material acts as a decoy receptor for binding of the spike proteins and inactivating the virus [48]. Based on these methods, the detection of antiviral property of textile samples is schematically represented in Fig. 4.

Recently, COVID-19 pandemic positively influenced the research in the field of antiviral textile. AgNPs have been effective agent against SARS-CoV-2 and suggested to be used in the range of ranging between 1 and $10 \mathrm{ppm}$ as these particles also demonstrated cytotoxic effect at concentrations of $20 \mathrm{ppm}$ and above. They are also having the potential to derange the environmental ecosystems, if not disposed of properly [9].

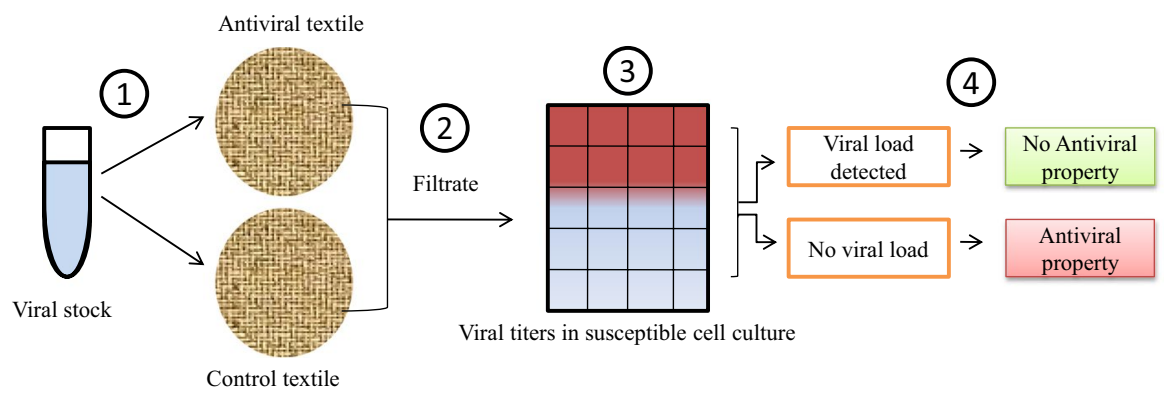

Fig. 4 Antiviral testing of textile: (1) incubation or passing of viral stock culture through the textile sample, (2) filtration through $0.22 \mu \mathrm{m}$ filters, (3) dilution and inoculation filtrate to susceptible cells and (4) after incubation plaque assay confirms the presence or absence of virus and its subsequent antiviral property 


\section{Leaching and non-leaching-type antimicrobial textile}

Finished fabrics are tested for leaching of antimicrobial agents. Most of the textiles having intrinsic antimicrobial property generally belong to the non-leaching type, while coated fabric needs to be tested for leaching of antimicrobial compounds. This test is done by simply soaking the finished material into distilled water, or washing with a detergent solution and nonionic surfactant. The sample is repeatedly washed or treated with a number of solvents to confirm the leaching out of the antimicrobial compound. This may be confirmed by testing the washed sample against different microorganisms. Reduced concentration of antimicrobial agents may ultimately lead to decreased antimicrobial activity. The leaching and non-leaching nature of the antimicrobial textile can be determined by observing the diffusion of the active compound into agar during agar well diffusion assay. A larger zone of inhibition around the tested fabric represents higher leaching potential, while a smaller zone represents lower diffusion of the compound. A small and consistent zone of inhibition after a number of laundry cycles confirms the non-leaching nature of the antimicrobial textile. Reduction in the size of the zone of inhibition indicates a leaching type of antimicrobial textile (Fig. 5).

A non-leaching type functional textile is generally preferred as it may retain its activity for a longer time and thus considered safe for direct skin contact. Bacterial biofilms are considered to be an important factor of pathogenic microbes. Some antimicrobial textiles have been prepared to reduce the biofilm formation ability or even destroying the biofilms. Bioactive molecules like eugenol and fluoroquinolone derivatives incorporated onto the cotton fabric surface through a triazine moiety minimized the leaching. The fluoroquinolone treated cotton fabric demonstrated bacteriostatic action against $S$. aureus in the planktonic as well as a preformed
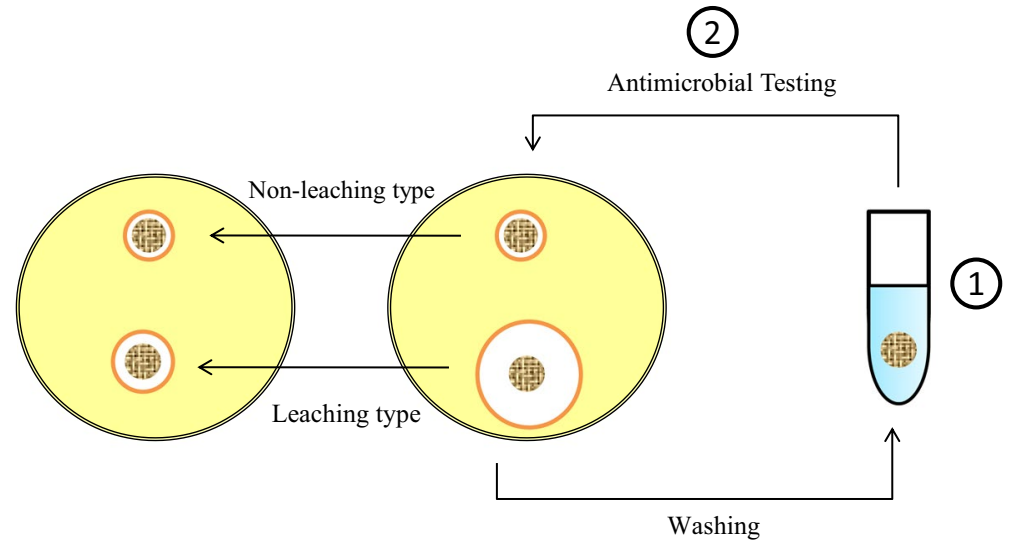

(3)

Fig. 5 Confirmation of leaching and non-leaching type textile: (1) washing of prepared textile sample, (2) placing of sample on agar plate pre-inoculated with the test bacteria and measurements of zone of inhibition and (3) repeated washing of same sample and following the previous step to confirm the leaching or non-leaching nature of the textile 
biofilm. Similarly, eugenol treated fabric actively eradicated the preformed $P$. aeruginosa biofilms [49]. Isocyanate group containing quaternary ammonium salt was developed as a potential agent for non-leaching type antimicrobial cotton fabric by a dipping-padding-drying process. Treated cotton fabric demonstrated excellent bactericidal activity against $S$. aureus and $E$. coli even after 50 washing cycles, while no adverse effect on the skin [50]. A transparent coating on cotton textile using quaternary ammonium-modified triethoxysilane was developed by sol-gel process, which demonstrated its permanent non-leaching antibacterial finish. The significant antimicrobial activity against $S$. aureus and $E$. coli was observed even after 15 washing cycles [51]. Some antimicrobial cotton fabrics prepared through polyhexamethylene guanidine hydrochloride and polypropylene glycol diglycidyl ether demonstrated a significant antimicrobial activity even after laundered with detergent solution [52].

Developing leaching type and non-leaching type fabrics primarily depend upon the availability of technology and production cost as per the requirement. Leaching type may be more biocidal as compared to non-leaching type, which may be biostatic or biorepellent, depending upon the antimicrobial agent, production technique and type of fibers (Fig. 6). Recently, different fabrics including natural (plantderived or animal-derived), synthetic and blended have been used to develop antimicrobial textile to enhance their efficiency against different microorganisms (Table 2).

\section{Natural fabric, antimicrobial dyes and pigments}

Traditionally the natural dyes and pigments were used for fabric staining, which not only gives color but also acts as an antimicrobial agent. Curcumin (1,7-bis(4hydroxy-3-methoxy)-1,6-heptadiene-3,5-dione), an active ingredient in turmeric

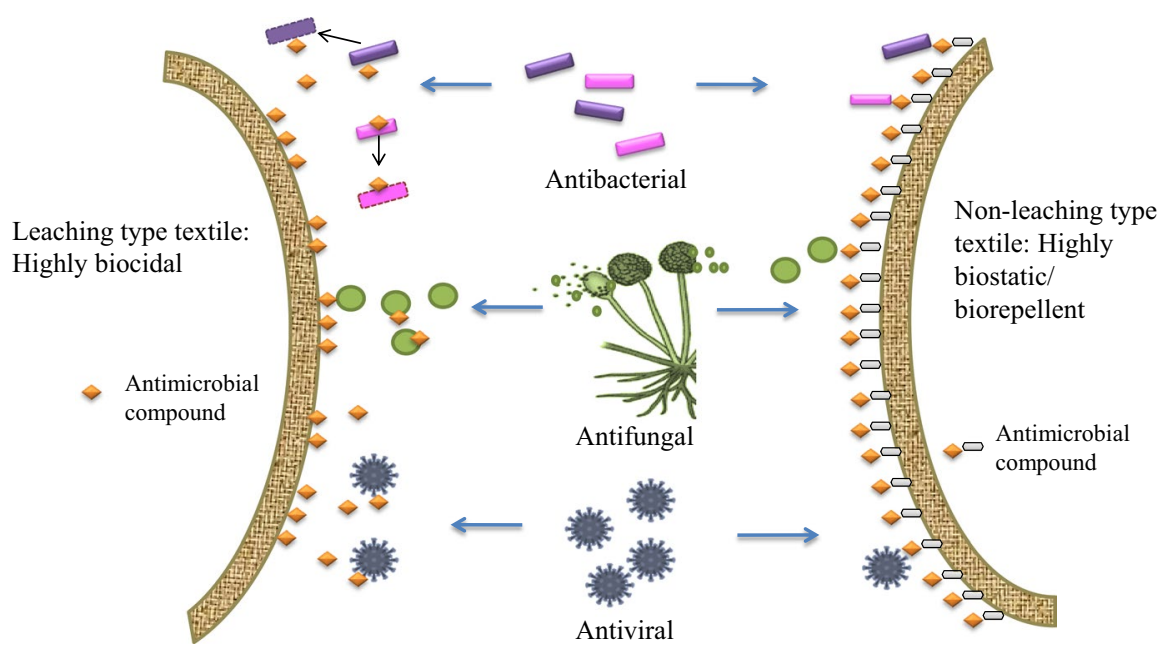

Fig. 6 Types of antimicrobial textile: leaching type may be more biocidal by releasing the active agents as compared to non-leaching type, which may be biostatic or biorepellent as it strongly binds the active agents 


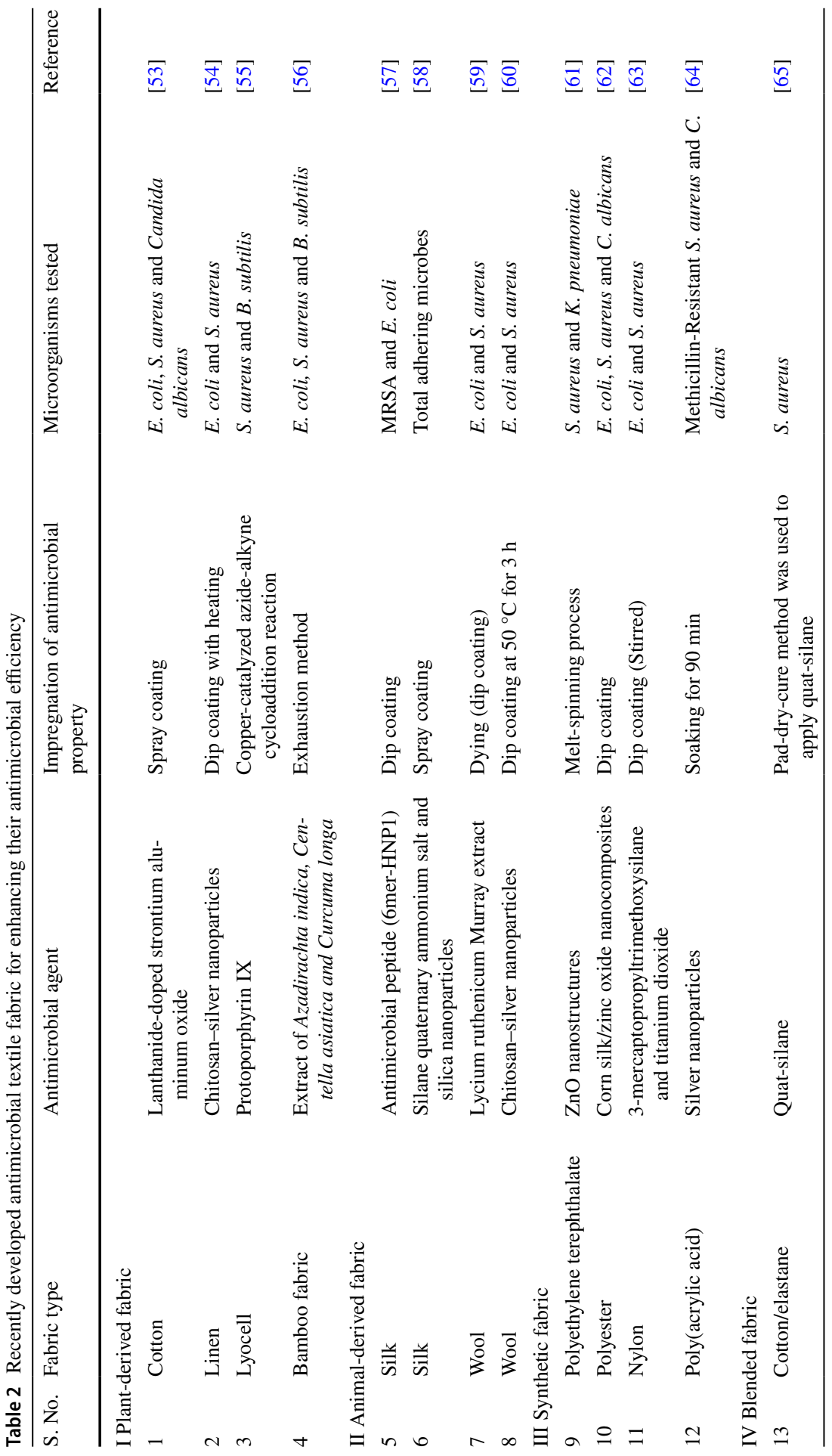




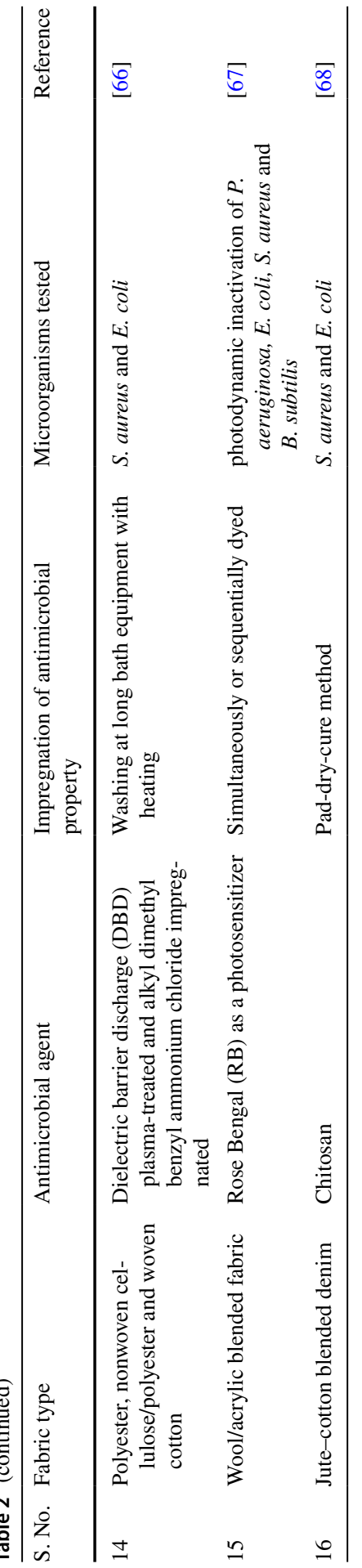


is commonly used as non-toxic natural dye. Fabric like wool and cotton have been well stained with curcumin and also investigated for their antimicrobial activity. As demonstrated by pad dyeing using curcumin onto wool and cotton imparted both, color as well as antimicrobial property. This treatment was also found to be highly resistant to common laundering practices as compared to the untreated one $[69,70]$. Cotton and other natural fibers exhibit excellent antimicrobial property when treated with natural compounds. Silk is considered to have natural antimicrobial property; however, it may not affect wide range of microbes. On the other hand, treatment with natural dyes like curcumin, or obtained from Terminalia catappa, Morinda citrofolia, Tectona grandis, Artocarpus heterophyllus, etc. have successfully imparted a significant level of antimicrobial activity against microorganisms [71].

Besides plants, microbial pigments have also been developed to dye cotton, glace cotton, silk and rayon. A red pigment isolated from Rhodonellum psychrophilum contained a mixture of 2-methyl-3-butyl-prodigine, prodigiosin, 2-methyl-3hexylprodigine, 3, 4-Didehydrorhodopsin, anhydrorhodovibrin, alloxanthin and tetradecanoyl-hexadecanoyl compounds. This pigment demonstrated antibacterial against E. coli, $S$. aureus and antiyeast activity against $C$. albicans and $S$. cerevisiae [72].

Sometimes alum or metal-based mordants such as salts of chromium, aluminum, iron, copper, stannous and tin along with solvents like petroleum ether, ethyl acetate, acetone and methanol are used to intensify the dying process. However, extensive use of these mordants may not be considered eco-friendly. On the other hand, several natural mordants including bark extracts, essential oils, tannic acid, sumac, gall nuts, neem oil, oleic, stearic acids, etc. are also in use [73]. The application of natural mordant is continuously being explored to enhance the dying process along with its antimicrobial activity. Wool and silk fibers pretreated with neem oil retained higher color when dyed with chlorophyll, saffron red and yellow natural dyes natural as compared to untreated fibers [74]. Similarly, natural mordant myrobalan has also been used along with a natural dye extracted from Opuntia ficus-indica fruit on the silk fabric to enhance its antimicrobial property [75].

Besides natural or synthetic mordants, experiments with natural dyes obtained from Green walnut shells and Neem leaves suggested that the increased concentration of dyes also enhanced the antimicrobial property of the silk fabric [76, 77]. A number of synthetic dyes have also been investigated for their antimicrobial activity. However, they are not considered as skin or environmental friendly.

\section{Synthetic and blended fabric}

Synthetic fibers including acrylic, nylon, polyester, polypropylene and tetrafluoroethylene may have some antimicrobial properties, which can further be enhanced through the treatment of antimicrobial compounds [78]. 3-Allyl-5,5-dimethylhydantoin $(\mathrm{ADMH})$ was grafted on several popular textiles like nylon, polyester, acrylic, polypropylene and natural fabrics to increase their antimicrobial property [79].

Antimicrobial agents and their incorporation into the fabric depend upon the type of textile materials and fibers. Chemical as well as physical properties of the fibers including their thickness diameter and processing conditions, antimicrobial 
compounds can be integrated using different methods and techniques. These compounds can be added directly into a fiber during its synthesis or into the fiber sheath during extrusion or may be applied on the fibers once they are manufactured through dip coating, polymer coating, spray application, or by introducing into the spin finish. In the case of nonwoven products, antimicrobials can be incorporated either during the bonding or during finishing processes. On the other hand, knitted or woven textiles are typically treated through exhaust and pad-dry-cure method [80].

Graphene-modified performance textile for personal clothing has been suggested to have a high level of antimicrobial activity and can be economic as well as comfortable. This graphene-based textile includes graphene 81 and graphene 82 nanomaterials impregnated fabrics. On the basis of their properties, these materials have been suggested for the fabrication of improved personal protective equipment (PPE) [81]. Cotton/elastane fabrics used for clothing achieved a significant level of antimicrobial property when treated with quat-silane [65]. Nylon 6 was containing copper nanoparticles (size 40-60 $\mathrm{nm}$ ) were physisorbed on a modified surface by grafting mPEG. The treated fabric demonstrated its activity against pathogenic bacteria and also ensured cytocompatibility [82]. Hybrid coatings based on $\mathrm{ZnO}, \mathrm{Ag}: \mathrm{ZnO} /$ chitosan, 3-glycidyloxypropyltrimethoxysilane and tetraethoxysilane prepared by sol-gel method were applied on pure cotton and cotton/polyester $(50 / 50 \%)$ textiles using 'pad-dry-cure' technique demonstrated a significant level of antimicrobial activity [83].

\section{Antimicrobial textiles for dermatological applications}

Antimicrobial textile materials are used for different purposes including first aid, in clinical and hygienic practice. These antimicrobial textiles may also be used as bio-functional textiles, which are produced by integrating advanced pharmaceutical nanocarriers to conventional textiles in order to provide wearable drug delivery systems. These bio-functional textiles are promising products that may improve the dermal penetration with lower toxicity risk [84]. Antimicrobial textile materials can be used as a suitable matrix for different active substances facilitating their gradual release. Beside antimicrobial substances, these textiles may be used as carrier in aromatherapy, atopic dermatitis, painkillers, hormone therapy, melanoma, psoriasis treatment, etc. [85]. Recent study suggested that lyocell and antimicrobial silver-impregnated textiles are promising on common atopic dermatitis [86]. Adhesion and penetration ability of Ag NPs on cotton fabric suggested them to be used as dressing material for wound healing. These highly efficient antimicrobial cotton fabrics also demonstrated no toxic effect on human cells [87]. Cotton wound dressing has been developed to treat skin fungal infections. This cotton wound dressing contained Ketoconazole and $\beta$-cyclodextrin that demonstrated a controlled and slow release of these antifungal compounds to kill skin fungus namely C. albicans and A. niger [88]. 


\section{Antimicrobial textile in functional design}

Antimicrobial clothes are innovative, growing and highly competitive in the apparel industry. These antimicrobial textiles have been used to fight bacteria in an innovative way, where fashion and design are the prime importance. However, awareness and use of such products may be limited. A study on the buying behavior of antimicrobial apparel such as baby clothes, socks and underwear in Bangkok metropolitan revealed that the buying majorities were female, mostly employed and aged between 32 and 38 years [89]. As breathable, antibacterial and antimicrobial breast support, bra and related apparel were much demanded by the woman's apparel industry; a breast support system has been patented. This design consists of a support member having an outer surface and an inner surface. This support member comprises at least one antibacterial and one antimicrobial material along with at least one anti-absorbent material or a combination thereof [90]. Besides this, men's designer antimicrobial undergarments are also in use. A patent on men's underwear included four 140D antimicrobial nylon yarns in a weaving process. It also involved drawing a graph by graphic software and slackening the density of the crotch by using an overlapping function, so that the slackened crotch was combined with the added 140D antimicrobial yarns and the stitch uplifting weave to form a bag [91].

Antimicrobial sportswear is also in demand as it may be useful in preventing microbial growth and sweating odor. Sensory analysis on sportswear with odorcontrolling property revealed that odor-control textile may smell less intense than similar polyester samples [92]. A flexible antimicrobial sleeve has been patented, which eliminates any germ transferred from the wearer to the sleeve by coughing or sneezing. This sleeve was designed to be worn by children on the elbow over their existing clothes. The design permitted a frictional fit that allowed the wearer easy application and removal without limiting the motions [93].

The application of antimicrobial clothing is not just limited to routing use, but it also seems to have a potential role in diverse fields. Recently, an evaluation analysis on developing antimicrobial textile for long-duration space flight has been carried out. The space travel system is generally free from microbes and there are quite lesser chances of microbial growth in the spacesuit. However, the garments in space are worn for a longer time and only a few garments are taken on a mission due to the lack of laundry facility. Contact with human skin may allow the growth of microbes and there are no options available for efficient washing of clothes. The use of antimicrobial textile in space travel may eliminate or reduce the need for garment washing [94].

Recently, the COVID-19 pandemic has generated a significant increase in the production and use of metal nanoparticles-based antiviral textile including face masks, gloves, protective suits, shoes, etc. Mismanagement in the disposal of such types of personal protective equipment may lead to a long-term negative effect in environments [95]. Sometimes leaching of metals for the nanometalbased textile can be used to calculate the amount of metal released in the disposal phase of such textile products during landfill treatment [96]. 


\section{Antimicrobial textile in fashion design}

Antimicrobial textiles have been used in the areas of health care, hygiene, medical devices, sportswear, innerwear, food packaging, storage, thermal and mechanical protection, automotive textiles, heating, ventilation and air conditioning, air filters, and water purification systems. They are also used to protect healthcare personnel with functional clothing as well as fabrics all around the home, including socks, mattresses, baby diapers, coverings and now in face masks as well. Antimicrobial textiles are quite popular with sportswear or active fashion wear. In the global and Indian fashion market, sportswear or active-wear is in gaining high popularity. Perhaps this shift is due to people's interest in different looks for different sports events inspired by various celebrities such as new gymnasium looks or casual active-wear. In recent time, we can also find many celebrities coming up with their sports or active-wear fashion brands such as HRX-lifestyle brand by Hrithik Roshan, SKULT - athleisure fashion brand by Shahid Kapoor or One $8 \mathrm{x}$ Puma and One8 Commune by Virat Kohli collaboration with Puma and there are many such names. Hence, these sports garments using specialized fibers, yarns, engineering design of fabric with various chemical finishes. In a textile preferable used for sport application, moisture and heat management are the key issues that have to be ensured for appropriate thermophysiological and tactile comfort and further due to the COVID-19 pandemic the demand for antimicrobial textiles in active sportswear is enormously increased [97]. Some examples of the textile and apparel companies/brands using antimicrobial fabrics are as follows:

- Brooks Brothers (USA), Antibacterial fabric for underwear

- Louvolite (England), Antimicrobial curtain fabric for window coverings

- Medline (USA), Antimicrobial fabric for medical devices

- Plastisan (Spain), Antimicrobial shower curtains

- QuietWear (USA), Anti-odor apparel for hunting

- St. Croix (USA), Antibacterial fabric for apparel

- EcoMed (Australia), Antibacterial hospital curtains

- Coleman Aerobed (USA), Antimicrobial air mattresses

- Sea to Summit (Australia), Antimicrobial sleeping bag liners and air mattresses

While certain global brands are claiming to use antimicrobial fabrics such as diesel claims that their new denim has virus-fighting capabilities [98], according to sources, it has the capacity to disable over 99 percent of viral activity within two hours of contact. 'London-based Apposta promises its dress shirts' fabric inhibits 'hosting bacteria and viruses, including COVID-19,' and 'reduces the likelihood and speed of contaminations, transmissions by destroying bacteria and viruses on contact' [99]. The Lululemon active sportswear brand, one of their lines called 'Silverescent,' products that boast of their antimicrobial properties through the use of silver threads. Companies like Dow Microbial Control, Microban, Lululemon, Under Armour, etc., manufacture products that guarantee sweat 
stain-free and bacteria-killing technology. Lululemon uses X-Static technology, which embeds $99.9 \%$ pure silver in its fibers. Companies rely on the chemical energy and reactions in their materials to deliver their antimicrobial qualities [100].

Companies such as Donear Industries, Welspun India Ltd, RSWM Ltd (Mayur), Arvind Ltd, Vardhman Textiles and D' Décor have launched antiviral fabrics for the garment manufacturing industry and home furnishing products. These fabrics are almost 15 to 20 percent higher in cost than the fabrics with no such treatment. Liva sub-brand of Aditya Birla group claims Antimicrobial protection is a special viscose-based fabric that inhibits the growth of microbes (Bacteria and Viruses) on Apparels \& Home-Textiles and kills them to the extent of $99 \%$ effective even after 50 washes [101].

\section{Conclusion and future directions}

Synthetic as well as natural fabrics have been used for antimicrobial textiles development. Antimicrobial properties can be introduced by application of chemicals, metal-based NPs, plant \& animal-derived compounds, dyes and mordants. The coated fabrics may show a narrow or broad range of antibacterial properties against bacteria, fungi and viruses. $\mathrm{MIC}$ and $\mathrm{IC}_{50}$ values can be used to evaluate the amount of antimicrobial compound to be coated, which affects the efficiency and price of prepared textiles. Synthetic chemicals and metal nanoparticles-based antimicrobial textiles are effective but also seem to be a threat toward damaging the environment as there is very limited information available about the exact impact of chemicals that can leach into the environment. Thus, future research must be directed toward exploring the potential for natural antimicrobial agents. As the application of domestic antimicrobial textiles is increasing, there must be a well-planned and managed system for the disposal and treatment of antimicrobial textiles. A consistent and robust solution is a must so that this should not become a problem like plastic waste management.

Authors' Contributions RG drafted antimicrobial agent part, SS drafted application and fashion-related part, and RKS conceptualized, edited and finalized the manuscript.

Data Availability Data are available in public resource.

Declarations

Conflicts of interest Not applicable

Consent for publication Yes.

Consent to participate Yes. 


\section{References}

1. Sanders D, Grunden A, Dunn RR (2021) A review of clothing microbiology: the history of clothing and the role of microbes in textiles. Biol Lett 17:rsbl.2020.0700. https://doi.org/10.1098/rsbl. 2020.0700

2. Lipp-Symonowicz B, Sztajnowski S, Wojciechowska D (2011) New commercial fibres called "bamboo fibres" - Their structure and properties. Fibres Text East Eur 84:18-23

3. Rajendran R (2010) Biotechnological application in textile Industry-Antimicrobial textiles. In: Maheshwari DK, Dubey RC, Saravanamuthu R (eds) Industrial Exploitation of Microorganisms. I K International Publishing House, New Delhi, India, p 129

4. Epstein L (2014) Fifty years since silent spring. Annu Rev Phytopathol 52:377-402. https://doi. org/10.1146/annurev-phyto-102313-045900

5. Morris H, Murray R (2020) Medical textiles Text Prog 52:1-127. https://doi.org/10.1080/00405 167.2020.1824468

6. Iyigundogdu ZU, Demir O, Asutay AB, Sahin F (2017) Developing novel antimicrobial and antiviral textile products. Appl Biochem Biotechnol 181:1155-1166. https://doi.org/10.1007/ s12010-016-2275-5

7. Nadi A, Boukhriss A, Bentis A et al (2018) Evolution in the surface modification of textiles: a review. Text Prog 50:67-108. https://doi.org/10.1080/00405167.2018.1533659

8. Shahid-ul-Islam S-I, Butola BS, Mohammad F (2016) Silver nanomaterials as future colorants and potential antimicrobial agents for natural and synthetic textile materials. RSC Adv 6:44232-44247. https://doi.org/10.1039/C6RA05799C

9. Jeremiah SS, Miyakawa K, Morita T et al (2020) Potent antiviral effect of silver nanoparticles on SARS-CoV-2. Biochem Biophys Res Commun 533:195-200. https://doi.org/10.1016/j.bbrc.2020. 09.018

10. Román LE, Gomez ED, Solís JL, Gómez MM (2020) Antibacterial cotton fabric functionalized with copper oxide nanoparticles. Molecules 25:5802. https://doi.org/10.3390/molecules25245802

11. Sadalage PS, Nimbalkar MS, Sharma KKK et al (2020) Sustainable approach to almond skin mediated synthesis of tunable selenium microstructures for coating cotton fabric to impart specific antibacterial activity. J Colloid Interface Sci 569:346-357. https://doi.org/10.1016/j.jcis.2020.02. 094

12. Kim BM, Van Minh N, Choi HY, Kim WG (2019) Coralmycin derivatives with potent anti-gram negative activity produced by the myxobacteria corallococcus coralloides M23. Molecules. https:// doi.org/10.3390/molecules24071390

13. Pandimurugan R, Thambidurai S (2017) UV protection and antibacterial properties of seaweed capped ZnO nanoparticles coated cotton fabrics. Int J Biol Macromol 105:788-795. https://doi.org/ 10.1016/j.ijbiomac.2017.07.097

14. El-Naggar ME, Shaarawy S, Hebeish AA (2018) Multifunctional properties of cotton fabrics coated with in situ synthesis of zinc oxide nanoparticles capped with date seed extract. Carbohydr Polym 181:307-316. https://doi.org/10.1016/j.carbpol.2017.10.074

15. Zhang G, Wang D, Yan J et al (2019) Study on the photocatalytic and antibacterial properties of TiO2 nanoparticles-coated cotton fabrics. Mater (Basel) 12:2010. https://doi.org/10.3390/ma121 22010

16. Salat M, Petkova P, Hoyo J et al (2018) Durable antimicrobial cotton textiles coated sonochemically with $\mathrm{ZnO}$ nanoparticles embedded in an in-situ enzymatically generated bioadhesive. Carbohydr Polym 189:198-203. https://doi.org/10.1016/j.carbpol.2018.02.033

17. Singh N, Sahu O (2019) Sustainable cyclodextrin in textile applications. In: The Impact and Prospects of Green Chemistry for Textile Technology. Elsevier, pp 83-105

18. Sunthornvarabhas J, Liengprayoon S, Lerksamran T et al (2019) Utilization of lignin extracts from sugarcane bagasse as bio-based antimicrobial fabrics. Sugar Tech 21:355-363. https://doi.org/10. 1007/s12355-018-0683-2

19. Benltoufa S, Miled W, Trad M et al (2020) Chitosan hydrogel-coated cellulosic fabric for medical end-use: Antibacterial properties, basic mechanical and comfort properties. Carbohydr Polym 227:115352. https://doi.org/10.1016/j.carbpol.2019.115352

20. Chen G, Haase H, Mahltig B (2019) Chitosan-modified silica sol applications for the treatment of textile fabrics: a view on hydrophilic, antistatic and antimicrobial properties. J Sol-Gel Sci Technol 91:461-470. https://doi.org/10.1007/s10971-019-05046-8 
21. Akalin GO, Oztuna Taner O, Taner T (2021) The preparation, characterization and antibacterial properties of chitosan/pectin silver nanoparticle films. Polym Bull. https://doi.org/10.1007/ s00289-021-03667-0

22. Chien H-W, Chiu T-H (2020) Stable N-halamine on polydopamine coating for high antimicrobial efficiency. Eur Polym J 130:109654. https://doi.org/10.1016/j.eurpolymj.2020.109654

23. Zhao T, Chen Q (2016) Halogenated phenols and polybiguanides as antimicrobial textile finishes. In: Antimicrobial Textiles. Elsevier, pp 141-153

24. Li S, Lin X, Liu Y et al (2019) Phosphorus-nitrogen-silicon-based assembly multilayer coating for the preparation of flame retardant and antimicrobial cotton fabric. Cellulose 26:4213-4223. https:// doi.org/10.1007/s10570-019-02373-5

25. Zhou C-E, Kan C, Yuen CM et al (2016) Plasma treatment applied in the pad-dry-cure process for making rechargeable antimicrobial cotton fabric that inhibits S. Aureus Text Res J 86:2202-2215. https://doi.org/10.1177/0040517515622147

26. Ražić SE, Glogar MI, Peran J et al (2020) Plasma pre-treatment and digital ink jet technology: A tool for improvement of antimicrobial properties and colour performance of cellulose knitwear. Mater Today Proc 31:S247-S257. https://doi.org/10.1016/j.matpr.2019.11.243

27. Ribeiro AI, Senturk D, Silva KK et al (2019) Antimicrobial efficacy of low concentration PVP-silver nanoparticles deposited on DBD plasma-treated polyamide 6,6 fabric. Coatings 9:581. https:// doi.org/10.3390/coatings9090581

28. Bonaldi RR (2018) Functional finishes for high-performance apparel. In: High-Performance Apparel. Elsevier, pp 129-156

29. El-Naggar ME, Shaarawy S, Hebeish AA (2018) Bactericidal finishing of loomstate, scoured and bleached cotton fibres via sustainable in-situ synthesis of silver nanoparticles. Int J Biol Macromol 106:1192-1202. https://doi.org/10.1016/j.ijbiomac.2017.08.127

30. Brzezinski S, Jasiorski M, Maruszewski K, et al (2007) Bacteriostatic textile-polymeric coat materials modified with nanoparticles. Polimery 52:362-366. https://doi.org/10.14314/polimery.2007. 362

31. Brzeziński S, Malinowska G, Kowalczyk D, et al (2012) Antibacterial and fungicidal coating of textile-polymeric materials filled with bioactive nano-and submicro-particles. Fibres Text East Eur 90:

32. Alonso D, Gimeno M, Olayo R et al (2009) Cross-linking chitosan into UV-irradiated cellulose fibers for the preparation of antimicrobial-finished textiles. Carbohydr Polym 77:536-543. https://doi. org/10.1016/j.carbpol.2009.01.027

33. Balagna C, Perero S, Percivalle E et al (2020) Virucidal effect against coronavirus SARS-CoV-2 of a silver nanocluster/silica composite sputtered coating. Open Ceram 1:100006. https://doi.org/10. 1016/j.oceram.2020.100006

34. Bueno J (2015) Antimicrobial Models in Nanotechnology. In: Nanotechnology in Diagnosis, Treatment and Prophylaxis of Infectious Diseases. Elsevier, pp 19-38

35. Bancalari E, Martelli F, Bernini V et al (2020) Bacteriostatic or bactericidal? Impedometric measurements to test the antimicrobial activity of Arthrospira platensis extract. Food Control 118:107380. https://doi.org/10.1016/j.foodcont.2020.107380

36. Khatami M, Sharifi I, Nobre MAL et al (2018) Waste-grass-mediated green synthesis of silver nanoparticles and evaluation of their anticancer, antifungal and antibacterial activity. Green Chem Lett Rev 11:125-134. https://doi.org/10.1080/17518253.2018.1444797

37. Cuce M, Kilinc M, Kilinc N et al (2020) Color, fastness and antimicrobial properties of wool fabrics dyed with helichrysum arenarium subsp. Aucheri Extract J Nat Fibers. https://doi.org/10.1080/ 15440478.2020.1848706

38. Igal K, Vázquez P (2020) Antimicrobial Fabrics Impregnated with Ag Particles Included in Silica Matrices. In: Waste in Textile and Leather Sectors. IntechOpen

39. Nabipour H, Wang X, Rahman MZ et al (2020) An environmentally friendly approach to fabricating flame retardant, antibacterial and antifungal cotton fabrics via self-assembly of guanazolemetal complex. J Clean Prod 273:122832. https://doi.org/10.1016/j.jclepro.2020.122832

40. Sharma JL, Dhayal V, Sharma RK (2021) White-rot fungus mediated green synthesis of zinc oxide nanoparticles and their impregnation on cellulose to develop environmental friendly antimicrobial fibers. 3 Biotech 11:269. https://doi.org/10.1007/s13205-021-02840-6

41. Tzanov T (2017) Pre-commercial lines for production of surface nanostructured antimicrobial and anti-biofilm textiles, medical devices and water treatment membranes 
42. Jaśkiewicz M, Janczura A, Nowicka J, Kamysz W (2019) Methods used for the eradication of staphylococcal biofilms. Antibiotics 8:174. https://doi.org/10.3390/antibiotics8040174

43. Staneva D, Vasileva-Tonkova E, Yordanova S et al (2020) Spectral characterization, antimicrobial and antibiofilm activity of poly(propylene imine) metallodendrimers in solution and applied onto cotton fabric. Int J Polym Anal Charact 25:374-384. https://doi.org/10.1080/1023666X.2020. 1796105

44. Wang L, Natan M, Zheng W et al (2020) Small molecule-decorated gold nanoparticles for preparing antibiofilm fabrics. Nanoscale Adv 2:2293-2302. https://doi.org/10.1039/D0NA00179A

45. Vasileva-Tonkova E, Staneva D, Medel S et al (2019) Antimicrobial, antibiofilm and cytotoxicity activity of a new acridine hyperbranched polymer in solution and on cotton fabric. Fibers Polym 20:19-24. https://doi.org/10.1007/s12221-019-8687-4

46. Ren T, Dormitorio TV, Qiao M et al (2018) N-halamine incorporated antimicrobial nonwoven fabrics for use against avian influenza virus. Vet Microbiol 218:78-83. https://doi.org/10.1016/j.vetmic.2018.03.032

47. Seino S, Imoto Y, Kosaka T et al (2016) Antiviral activity of silver nanoparticles immobilized onto textile fabrics synthesized by radiochemical process. MRS Adv 1:705-710. https://doi.org/10. 1557/adv.2016.43

48. Otto DP, de Villiers MM (2020) Layer-by-layer nanocoating of antiviral polysaccharides on surfaces to prevent coronavirus infections. Molecules 25:3415. https://doi.org/10.3390/molecules2 5153415

49. Montagut AM, Granados A, Lazurko C et al (2019) Triazine mediated covalent antibiotic grafting on cotton fabrics as a modular approach for developing antimicrobial barriers. Cellulose 26:74957505. https://doi.org/10.1007/s10570-019-02584-w

50. Gu J, Yuan L, Zhang Z et al (2018) Non-leaching bactericidal cotton fabrics with well-preserved physical properties, no skin irritation and no toxicity. Cellulose 25:5415-5426. https://doi.org/10. 1007/s10570-018-1943-8

51. Saif MJ, Zia KM, Rehman F et al (2015) An eco-friendly, permanent and non-leaching antimicrobial coating on cotton fabrics. J Text Inst 106:907-911. https://doi.org/10.1080/00405000.2014. 952137

52. Li Z, Chen J, Cao W et al (2018) Permanent antimicrobial cotton fabrics obtained by surface treatment with modified guanidine. Carbohydr Polym 180:192-199. https://doi.org/10.1016/j.carbpol. 2017.09.080

53. Khattab TA, Fouda MMG, Abdelrahman MS et al (2019) Development of illuminant glow-in-thedark cotton fabric coated by luminescent composite with antimicrobial activity and ultraviolet protection. J Fluoresc 29:703-710. https://doi.org/10.1007/s10895-019-02384-2

54. Shahid-ul-Islam BBS, Verma D (2019) Facile synthesis of chitosan-silver nanoparticles onto linen for antibacterial activity and free-radical scavenging textiles. Int J Biol Macromol 133:1134-1141. https://doi.org/10.1016/j.ijbiomac.2019.04.186

55. Fadavi F, Abdulkhani A, Hamzeh Y et al (2019) Photodynamic antimicrobial cellulosic material through covalent linkage of protoporphyrin IX onto lyocell fibers. J Wood Chem Technol 39:5774. https://doi.org/10.1080/02773813.2018.1500605

56. Syed Zameer Ahmed S, Balu N, Khader SZA, et al (2020) Fabrication and evaluation of bamboo fabric coated with extracts of Curcuma longa, Centella asiatica and Azadirachta indica as a wound dressing material. Adv Tradit Med. https://doi.org/10.1007/s13596-020-00503-0

57. Franco AR, Fernandes EM, Rodrigues MT et al (2019) Antimicrobial coating of spider silk to prevent bacterial attachment on silk surgical sutures. Acta Biomater 99:236-246. https://doi.org/10. 1016/j.actbio.2019.09.004

58. Aslanidou D, Karapanagiotis I (2018) Superhydrophobic, superoleophobic and antimicrobial coatings for the protection of silk textiles. Coatings 8:101. https://doi.org/10.3390/coatings8030101

59. Dong Y, Gu J, Wang P, Wen H (2019) Developed functionalization of wool fabric with extracts of Lycium ruthenicum Murray and potential application in healthy care textiles. Dye Pigment 163:308-317. https://doi.org/10.1016/j.dyepig.2018.12.011

60. Sadeghi-Kiakhani M, Hashemi E, Gharanjig K (2020) Treating wool fibers with chitosan-based nano-composites for enhancing the antimicrobial properties. Appl Nanosci 10:1219-1229. https:// doi.org/10.1007/s13204-019-01203-1

61. Hwang S-H, Kim YK, Seo H-J et al (2019) The morphological effects of ZnO upon the antimicrobial and deodorant activities of polyethylene terephthalate/ZnO composite filaments. J Nanosci Nanotechnol 19:7721-7728. https://doi.org/10.1166/jnn.2019.16848 
62. Amani A, Montazer M, Mahmoudirad M (2019) Synthesis of applicable hydrogel corn silk/ZnO nanocomposites on polyester fabric with antimicrobial properties and low cytotoxicity. Int J Biol Macromol 123:1079-1090. https://doi.org/10.1016/j.ijbiomac.2018.11.093

63. Lee G, Lee J, Kang C (2019) Strong and sustainable chemical bonding of TiO2 on nylon surface using 3-mercaptopropyltrimethoxysilane (3-MPTMS): analysis of antimicrobial and decomposition characteristics of contaminants. J Coatings Technol Res 16:1399-1409. https://doi.org/10. 1007/s11998-019-00222-5

64. Mofidfar M, Kim ES, Larkin EL et al (2019) Antimicrobial activity of silver containing crosslinked poly(Acrylic Acid) fibers. Micromachines 10:829. https://doi.org/10.3390/mi10120829

65. Yildız Varan N, Eryuruk SH (2018) The effects of quat-silane antimicrobials on the physical and mechanical properties of cotton and cotton/elastane fabrics used for clothing. IOP Conf Ser Mater Sci Eng 460:012004. https://doi.org/10.1088/1757-899X/460/1/012004

66. Song C, Strazar, et al (2019) Chemical, thermo-mechanical and antimicrobial properties of DBD plasma treated disinfectant-impregnated wipes during storage. Polymers (Basel) 11:1769. https:// doi.org/10.3390/polym11111769

67. Chen W, Chen J, Li L et al (2019) Wool/acrylic blended fabrics as next-generation photodynamic antimicrobial materials. ACS Appl Mater Interfaces 11:29557-29568. https://doi.org/10.1021/ acsami.9b09625

68. Khan AM, Islam MM, Khan MMR (2020) Chitosan incorporation for antibacterial property improvement of jute-cotton blended denim fabric. J Text Inst 111:660-668. https://doi.org/10. 1080/00405000.2019.1657220

69. Han S, YANG Y, (2005) Antimicrobial activity of wool fabric treated with curcumin. Dye Pigment 64:157-161. https://doi.org/10.1016/j.dyepig.2004.05.008

70. Reddy N, Han S, Zhao Y, Yang Y (2013) Antimicrobial activity of cotton fabrics treated with curcumin. J Appl Polym Sci 127:2698-2702. https://doi.org/10.1002/app.37613

71. Prusty AK, Das T, Nayak A, Das NB (2010) Colourimetric analysis and antimicrobial study of natural dyes and dyed silk. J Clean Prod 18:1750-1756. https://doi.org/10.1016/j.jclepro.2010.06. 020

72. Bisht G, Srivastava S, Kulshreshtha R et al (2020) Applications of red pigments from psychrophilic Rhodonellum psychrophilum GL8 in health, food and antimicrobial finishes on textiles. Process Biochem 94:15-29. https://doi.org/10.1016/j.procbio.2020.03.021

73. İşmal ÖE, Yıldırım L (2019) Metal mordants and biomordants. In: The Impact and Prospects of Green Chemistry for Textile Technology. Elsevier, pp 57-82

74. El-Khatib EM, Ali NF, El-Mohamedy RSR (2020) Influence of Neem oil pretreatment on the dyeing and antimicrobial properties of wool and silk fibers with some natural dyes. Arab J Chem 13:1094-1104. https://doi.org/10.1016/j.arabjc.2017.09.012

75. Ganesan P, Karthik T (2017) Analysis of colour strength, colour fastness and antimicrobial properties of silk fabric dyed with natural dye from red prickly pear fruit. J Text Inst 108:1173-1179. https://doi.org/10.1080/00405000.2016.1222862

76. UZKUL H, ALKAN R (2018) Antimicrobial Properties of Silk Fabrics Dyed with Green Walnut Shell (Juglans regia L.). Kocaeli J Sci Eng 1:28-32. https://doi.org/10.34088/kojose.410163

77. Abd El Aty AA, El-Bassyouni GT, Abdel-Zaher NA, Guirguis OW (2018) Experimental study on antimicrobial activity of silk fabric treated with natural dye extract from neem (Azadirachta indica) leaves. Fibers Polym 19:1880-1886. https://doi.org/10.1007/s12221-018-8239-3

78. Emam HE, Darwesh OM, Abdelhameed RM (2018) In-growth metal organic framework/synthetic hybrids as antimicrobial fabrics and its toxicity. Colloids Surfaces B Biointerfaces 165:219-228. https://doi.org/10.1016/j.colsurfb.2018.02.028

79. Sun Y, Sun G (2002) Durable and regenerable antimicrobial textile materials prepared by a continuous grafting process. J Appl Polym Sci 84:1592-1599. https://doi.org/10.1002/app.10456

80. El-Ola SMA (2008) Recent developments in finishing of synthetic fibers for medical applications. Des Monomers Polym 11:483-533. https://doi.org/10.1163/156855508X363816

81. Bhattacharjee S, Joshi R, Chughtai AA, Macintyre CR (2019) Graphene modified multifunctional personal protective clothing. Adv Mater Interfaces 6:1900622. https://doi.org/10.1002/admi.20190 0622

82. Swar S, Máková V, Horáková J et al (2020) A comparative study between chemically modified and copper nanoparticle immobilized Nylon 6 films to explore their efficiency in fighting against two types of pathogenic bacteria. Eur Polym J 122:109392. https://doi.org/10.1016/j.eurpolymj.2019. 109392 
83. Buşilă M, Muşat V, Textor T, Mahltig B (2015) Synthesis and characterization of antimicrobial textile finishing based on $\mathrm{Ag}: \mathrm{ZnO}$ nanoparticles/chitosan biocomposites. RSC Adv 5:2156221571. https://doi.org/10.1039/C4RA13918F

84. Massella A, Ferri, et al (2019) Bio-functional textiles: combining pharmaceutical nanocarriers with fibrous materials for innovative dermatological therapies. Pharmaceutics 11:403. https://doi. org/10.3390/pharmaceutics11080403

85. Atanasova D, Staneva D, Grabchev I (2021) Textile materials modified with stimuli-responsive drug carrier for skin topical and transdermal delivery. Mater (Basel) 14:930. https://doi.org/10. 3390/ma14040930

86. Fenton C, Al-Salama ZT (2021) Fabrics can greatly improve or exacerbate atopic dermatitis. Drugs Ther Perspect 37:157-161. https://doi.org/10.1007/s40267-021-00822-5

87. Elnaggar M, Emam H, Fathalla M, et al (2021) Chemical synthesis of silver nanoparticles in its solid state: highly efficient antimicrobial cotton fabrics for wound healing properties. Egypt $\mathrm{J}$ Chem 0-0. https://doi.org/10.21608/ejchem.2021.57667.3236

88. Hedayati N, Montazer M, Mahmoudirad M, Toliyat T (2020) Ketoconazole and Ketoconazole/ $\beta$ cyclodextrin performance on cotton wound dressing as fungal skin treatment. Carbohydr Polym 240:116267. https://doi.org/10.1016/j.carbpol.2020.116267

89. Taweehiransuwan N (2020) The Innovation of antimicrobial apparel affecting to consumer buying behaviour in Bangkok Metropolitan

90. Taghdiri M (2009) Antibacterial, anti-absorbent and antimicrobial breast supports, bras and related apparel

91. Xiaoge L (2016) Men's underwear

92. Klepp IG, Buck M, Laitala K, Kjeldsberg M (2016) What's the problem? odor-control and the smell of sweat in sportswear. Fash Pract 8:296-317. https://doi.org/10.1080/17569370.2016.12151 17

93. Bratskeir S (2017) Antimicrobial Arm Sleeve

94. Jagadeesan K (2018) Antimicrobial Textiles for Long Duration Space Flight. University of Rhode Island

95. Ardusso M, López ADF, Buzzi NS et al (2020) COVID-19 pandemic repercussions on plastic and antiviral polymeric textile causing pollution on beaches and coasts of South America. Sci Total Environ. https://doi.org/10.1016/j.scitotenv.2020.144365

96. Limpiteeprakan P, Babel S (2016) Leaching potential of silver from nanosilver-treated textile products. Environ Monit Assess 188:156. https://doi.org/10.1007/s10661-016-5158-x

97. Chowdhury P, Samanta KK, Basak S (2014) Recent development in textile for sportswear application. Int J Eng Res Technol 3:1905-1910

98. Polygiene (2021) VIRUS-FIGHTING DENIM FROM DIESEL. https://polygiene.com/virus-fight ing-denim-from-diesel/. Accessed 29 May 2021

99. Fernandez C (2020) Brands Claim Their Clothes Kill Viruses. Will Consumers Buy It? In: Bus. Fash. https://www.businessoffashion.com/articles/retail/antiviral-fashion-coronavirus-diesel. Accessed 7 Jan 2020

100. Lululemon (2020) Silverescent. https://info.lululemon.com/design/fabrics-technology/silverescent. Accessed 2 Jan 2020

101. Liva A (2020) CARE MADE FASHIONABLE. In: Liva. https://www.livafluidfashion.com/livaantimicrobial/. Accessed 7 Jan 2020

Publisher's Note Springer Nature remains neutral with regard to jurisdictional claims in published maps and institutional affiliations. 